\title{
The Impact of the Six-Week Walking on the Elderly's Happiness and Mental Health
}

\author{
Fatemeh Motaharinezhad, ${ }^{1,}{ }^{*}$ Pooran Madani, ${ }^{1}$ Sepideh Seyed, ${ }^{1}$ Karim Ayoubi Avaz, ${ }^{1}$ and Masomeh \\ Rasolzadeh $^{1}$ \\ ${ }^{1}$ Neuromuscular Rehabilitation Research Center, Semnan University of Medical Sciences, Semnan, IR Iran \\ "Corresponding author: Fatemeh Motaharinezhad, Neuromuscular Rehabilitation Research Center, Semnan University of Medical Sciences, Semnan, IR Iran. Tel: \\ +98-2333328502, E-mail: motahari201227@gmail.com
}

Received 2016 January 28; Revised 2016 April 23; Accepted 2016 April 23.

\begin{abstract}
Background: Aging is a sensitive period of human life and, considering the special needs and the behaviors that lead to mental health promotion and quality of life, this period is very important. The useful methods used to maintain mental health, reduce stress and make one more adaptive are doing physical activities and aerobic exercises. No studies in the past have investigated variety of exercises such as the role of hiking on mental health and happiness of elderly women.

Objectives: This study was done to evaluate the impact of the six-week hiking on happiness and mental health of elderly residing in Semnan.

Patients and Methods: Twenty-seven elderly women with a mean age of 61 years were randomly selected in two groups with available sampling; the case group with 14 participants and the control group with 13. The case group took part in walking exercises. Both groups completed the Persian Version of the oxford happiness inventory (OHI) before and after exercises. This inventory contains 29 items, which evaluates happiness components; self-esteem, positive mood, life satisfaction, efficiency and mental health.

Results: There was a significant difference in the self-esteem $(P=0.003)$, life satisfaction $(P=0.001)$, efficiency $(P=0.00)$, positive $\operatorname{mood}(\mathrm{P}=0.00)$, mental health $(\mathrm{P}=0.001)$ and happiness $(\mathrm{P}=0.001)$ among elderly women in the case group before and after a regular six-week walking program.

Conclusions: According to the results, walking increases the happiness and mental health of elderly women. Therefore, promoting the habit of walking as a public activity among elder women could have a significant impact on them.
\end{abstract}

Keywords: Walking, Elderly, Happiness, Mental Health

\section{Background}

Aging is a sensitive period for human beings and considering the issues and needs of elderly is essential. Elderly people, specially, older age women are part of the society in the modern world. A census conducted in Iran (2006) showed that $7.27 \%$ of the Iranian population, contains more than 5 million elderly individuals over 60 years old and will reach up to $14.70 \%$ within the next 20 years (1).

Therefore, with regards to the increasing elderly population, considering the specific needs of aging, paying attention to the behaviors for promoting health and quality of life is very important (1). Emotional status of the elderly is influenced by factors such as reducing physical health, physical weakness and reducing social relationships. The effective methods used to protect mental health, decrease stress and also make one more adaptive are doing physical and aerobic exercises (1). According to the statement of the world health organization (WHO), one of the ways to reduce medical care costs and improve health is to get elderly to participate in physical activities (2).
Studies have shown that physical exercise has positive effects on physical and mental health. In a meta-analysis performed by Plant and Rodin (3) to evaluate the impact of exercise on mental health, they concluded that doing exercises improved the mood, mental health, self-confidence and self-esteem in the participants. Macconville (4) considered nine factors in creating happiness and mental health and one of them was to engage in sports and physical activities.

The results showed that exercise was beneficial not only among young and middle-aged individuals, but also for the elderly. Reviewing the study of Blumenthal et al. (5), about the long-term effects of exercise on mental function among elderly women and men showed that people who had done the 14-month-aerobic exercise, had a10 \% to $15 \%$ aerobic capacity along with modest improvement in some mental factors.

Norvell and Belles (6) reported that depression was decreased by doing aerobics activities compared to other exercises. Turner (7) stated that people with less physical ex- 
ercise gained a lower average score in happiness than those with high levels of physical activity. Happiness had a direct relationship with improvement of the quality of appetite, sleep, memory, family relationships, friendship, family status and the elderly people's mental health and quality of life (8).

Studies in the past have shown physical exercises as effective factors in physical and mental health. However, the discussion on the impacts of physical and sport activities on physical and mental health of the elderly is continuing.

On the other hand, none of the former researches has investigated the effect of physical activities, such as walking, on mental health and happiness among elderly women. However, the WHO stated that to choose appropriate strategies of exercise to improve mental health, more studies are needed (2)

\section{Objectives}

This study evaluated the effect of the six-week walking on happiness and mental health of elderly women in Semnan.

\section{Patients and Methods}

In an experimental study, 27 elderly women residing in Semnan were selected via the available- sampling method and were randomly divided to case $(n=14)$ and control groups $(n=13)$. The inclusion criteria was age of $60-70$ years old with a score of cognitive test (MMSE) over 22, lack of exercises with no regular exercises in sport clubs, no history of severe cardio- pulmonary diseases, being active and independent, and having the ability to read and write. Those who did not have the mentioned conditions as well as those with diseases and complications during the study were excluded. This study was conducted with informed consent from all participants. Mini mental status examination (MMSE), which is a useful tool to evaluate cognitive function in elderly subjects, was used for cognitive screening. It includes 30 items and its reliability and validity has been confirmed for the Iranian population (9).

To measure happiness and mental health, the Persian version of the oxford happiness inventory was used, which was prepared in 1989 by Argyle and Lu (10). It contains 29 items, which evaluate happiness components; self-esteem, positive mood, life satisfaction, efficiency and mental health, and it also measures the final score of the individual's happiness. Multiple-choice questions were in the range of 0 to 3 . For the lack of the examined item; the score of "0", for low level; the score of "1", for medium level; the score of " 2 " and for "high grade"; the score of " 3 " was considered. The whole scale was from 0 to 87 . The reliability and validity of this questionnaire was determined $93 \%$ in Iran (11).

However, to ensure the content and validity of the questionnaire, it was distributed among a group of elderly individuals. The validity and reliability were assessed again using Cronbach's alpha. The reliability was $87 \%$. Both groups completed the Persian version of the oxford happiness inventory $(\mathrm{OHI})$ before the start of exercise. Next, the case group took walks for six weeks, three sessions per week, and 30 minutes for each session. It was slow and mild hiking with aerobic activities such as (stretching and exercise movements). Finally at the end of six weeks, again the Persian version of the oxford happiness Inventory was completed by the control and case groups. The scores were recorded for final scores.

Data normality was approved using the KolmogorovSmirnov test. To study the impact of walking exercises on the variables, Paired-T Test was used. To analyze the data, SPSS-20 was used.

\section{Results}

In this study, 27 non-athletic elderly women were randomly assigned to two experimental $(n=14)$ and control $(n=13)$ groups. Table 1 shows the demographic characteristics and base line data of each group. Also in Table 2, mean changes between case and control groups were compared and the results showed that there was a significant difference between self-esteem $(\mathrm{P}=0.003)$, life satisfaction $(\mathrm{P}=$ $0.001)$, efficiency $(\mathrm{P}=0.00)$, positive $\operatorname{mood}(\mathrm{P}=0.00)$, mental health $(\mathrm{P}=0.001)$ and happiness $(\mathrm{P}=0.001)$ of those who did exercise compared with those who did not do any exercise.

Table 1. Comparison of Demographic Characteristics and Base Line Measurements in the Experimental and Control Groups

\begin{tabular}{lccc}
\hline Variables & $\begin{array}{c}\text { Case group }(\mathbf{n}= \\
\text { 14) } \begin{array}{c}\text { Mean Changes } \\
(\text { SD })\end{array}\end{array}$ & $\begin{array}{c}\text { Control Group }(\mathbf{n}= \\
\text { 13), Mean Changes } \\
(\text { SD })\end{array}$ & P Value \\
\hline Age, $\mathbf{y}$ & $65.8(2.71)$ & $65.2(2.62)$ & 0.07 \\
\hline Weight, kg & $74.75(7.11)$ & $71.6(3.12)$ & 0.69 \\
\hline Height, cm & $169.4(3.34)$ & $167.3(3.11)$ & 0.87 \\
\hline Self-esteem & $2.28(1.76)$ & $2.16(1.69)$ & 0.160 \\
\hline Life satisfaction & $14.55(6.40)$ & $15.31(5.28)$ & 0.008 \\
\hline Effectiveness & $4.45(2.31)$ & $4.41(2.29)$ & 0.101 \\
\hline Positive mood & $11.22(3.80)$ & $10.17(3.11)$ & 0.005 \\
\hline Mental health & $7.57(2.74)$ & $7.55(2.71)$ & 0.112 \\
\hline Happiness & $37.28(13.56)$ & $38.30(13.88)$ & 0.001 \\
\hline
\end{tabular}


Table 2. Comparison of Mean Changes in Case and Control Groups Related to Mental Characteristics of the Elderly Women in Pre and Post Test

\begin{tabular}{lccc}
\hline Variables & $\begin{array}{c}\text { Case group }(\mathbf{n}=\mathbf{1 4}) \\
\text { Mean Changes } \\
(\mathbf{S D})\end{array}$ & $\begin{array}{c}\text { Control group }(\mathbf{n}= \\
\text { 13) }\end{array}$ & Pean Changes \\
$(\mathbf{S D})$ & \\
\hline Self-esteem & $3.27(1.75)$ & $2.33(1.79)$ & 0.003 \\
\hline Life satisfaction & $19.33(5.86)$ & $14.68(6.22)$ & 0.001 \\
\hline Effectiveness & $6.43(2.04)$ & $4.11(2.12)$ & 0.001 \\
\hline Positive mood & $14.22(3.92)$ & $9.97(3.00)$ & 0.001 \\
\hline Mental health & $9.70(3.09)$ & $7.50(2.65)$ & 0.001 \\
\hline Happiness & $48.47(12.36)$ & $38.13(13.76)$ & 0.001 \\
\hline
\end{tabular}

\section{Discussion}

The aim of this study was to investigate the impact of the six-week walking on the elderly's happiness and mental health. The results showed that there was a significant difference between self-esteem of elderly women before and after regular walking. In other words, the elderly people who participated in the physical exercise and sport activity compared with non-athletic elderly had a higher selfesteem, in accordance with the findings of previous studies.

Pronk et al. (12) in a psychophysical study conducted on women concluded that exercise could have beneficial effects on mood and behavior, and in addition, this type of exercises reduced stress and anxiety and also increased self-confidence. Also, the results showed that life satisfaction rate in elder women after doing exercise improved significantly after exercise.

Therefore, elderly women should optimally spend their time with precise planning and allocate leisure time to go to parks and sport halls, otherwise, they will spend most of their time in idleness. In addition, Norvell and Belles in a study conducted on officers concluded that physical activity improved cardiovascular fitness and decreased depression, anxiety and increased job satisfaction (6).

Given that the elderly due to their age conditions are at high risk of cardiovascular diseases, thus doing exercise, especially taking walks could reduce the incidence of these complications. Furthermore, there was a significant difference between the index of efficiency and positive mood of the elderly women before and after exercise. Clapp et al. (13) showed that physical exercise was effective on modifying the mood by two ways; releasing endorphins and reducing the level of cortisol, which is a hormone secreted in blood due to stress. Endorphins are natural remedies to reduce pain and cause pleasant feelings. Physical exercise can have an increasing effect on the level of endorphins.
Dilorenzo and some other researchers (14) concluded that proper physical exercise had a significant impact on increasing the level of serotonin (the effective hormone in modifying mood). It seems the body receives more endorphins by doing exercise and these substances are maintained for a longer period. The results showed that the athletic elderly woman had a better mental health status with high happiness. Norvell and Belles (6) showed that exercise programs had a large share in mental and physical health. Leonhardt (15) rejected this hypothesis: "money brings happiness". He believes that exercise is a powerful tool in reducing stress and increasing happiness.

Finally, it can be concluded that exercise and physical activity have major impacts on mental health and happiness among elderly women. It is evident that older people, who do exercise and physical activities have positive mental and physical health. As exercise, physical activity and walking are factors that promote mental health, happiness, self-esteem, life satisfaction, efficiency, positive mood and reduce stress, thus exercise is recommended for elder individuals. Based on the findings, regular walking programs are suggested for the elderly in order to improve their mental health and happiness and ultimately improve their quality of life.

\section{Acknowledgments}

We appreciate all those who assisted us in this study, as well as all participants who gave us their time.

\section{References}

1. National portal of statistics . 2006. Available from: www.sci.org.ir.

2. Sun F, Norman IJ, While AE. Physical activity in older people: a systematic review. BMC Public Health. 2013;13:449. doi: 10.1186/1471-245813-449. [PubMed: 23648225].

3. Plante TG, Rodin J. Physical fitness and enhanced psychological health. Current Psychol: Research and Review. 1990;9(1):3-24.

4. Macconville B. Revealed: nine ways to find your inner happiness 2003. Available from: www.thecostman.co.uk/inde:126272003.

5. Blumenthal JA, Emery CF, Madden DJ, George LK, Coleman RE, Riddle MW, et al. Cardiovascular and behavioral effects of aerobic exercise training in healthy older men and women. J Gerontol. 1989;44(5):M147-57. [PubMed: 2768768].

6. Norvell N, Belles D. Psychological and physical benefits of circuit weight training in law enforcement personnel.J Consult Clin Psychol. 1993;61(3):520-7. [PubMed: 8326055].

7. Turner A. An investigation into the relationship between physical activity levels and happiness in adults 2008. Available from: http: //chesterrepopenrepository.com.

8. Kawamoto R, Doi T, Yamada A, Okayama M, Tsuruoka K, Satho M, et al. [Happiness and background factors in community-dwelling older persons]. Nihon Ronen Igakkai Zasshi. 1999;36(12):861-7. [PubMed: 10689897].

9. Cockrell JR, Folstein MF. Mini-Mental State Examination (MMSE). Psychopharmacol Bull. 1988;24(4):689-92. [PubMed: 3249771]. 
10. Argyle M, Martin M, Lu L. Testing for stress and happiness: the role of social and cognitive factors. Stress Emotiontaylor Francis. 1995:173-87.

11. Alipour A, Nourbala AA, Ejei J, Motieyan H. Happiness and immunology performance. Psychol. 1379;40:219-33.

12. Pronk NP, Crouse SF, Rohack JJ. Maximal exercise and acute mood response in women. Physiol Behav. 1995;57(1):1-4. [PubMed: 7878100].

13. Clapp LL, Richardson MT, Smith JF, Wang M, Clapp AJ, Pieroni RE. Acute effects of thirty minutes of light-intensity, intermittent exercise on patients with chronic fatigue syndrome. Phys Ther. 1999;79(8):749-56. [PubMed: 10440661].

14. DiLorenzo TM, Bargman EP, Stucky-Ropp R, Brassington GS, Frensch PA, LaFontaine T. Long-term effects of aerobic exercise on psychological outcomes. Prev Med. 1999;28(1):75-85. doi: 10.1006/pmed.1998.0385. [PubMed: 9973590].

15. Leonhardt D. Investing as a sport? Money does not generally buy happiness 2002. Available from: www.Powerstressmanagment.com. 